\title{
ESTRATEGIAS PARA ANALIZAR EL DISCURSO RETÓRICO PUBLICITARIO: UN MODELO A TRAVÉS DE ANUNCIOS DE ESPAÑA Y PORTUGAL ${ }^{1}$
}

\author{
Aurora Martínez Ezquerro \\ Universidad de La Rioja
}

\begin{abstract}
RESUMEN: La publicidad tiene como objetivo prioritario la persuasión y con esta finalidad emplea todos los medios que se hallan a su alcance y que toma principalmente de la retórica. En el ámbito educativo, esta comunicación estratégica debe enfocarse adecuadamente desde una perspectiva complementaria que abarca los elementos compositivos y la reflexión crítica. Teniendo en cuenta que el tema que corresponde a los textos publicitarios forma parte del currículum de Bachillerato, se analizan las estrategias y modalidades utilizadas en manuales de este nivel. A partir de las carencias constatadas en estos libros de texto, se muestra un método global centrado en el fomento de las competencias comunicativas (orales y escritas) y en la interpretación de los mecanismos de la persuasión publicitaria; y puesto que permite realizar complementarias aplicaciones, se ejemplifica con un análisis comparado desde perspectiva intercultural de anuncios de vino de España y Portugal. En suma, este método de interpretación enmarcado en la E/A fomenta necesarias estrategias de comentario del discurso retórico publicitario en un contexto en el que los estudiantes deben ser formados para desarrollar la capacidad de interpretar el mundo y de crear sus propias opiniones.
\end{abstract}

PALABRAS CLAVE: publicidad, discurso retórico, estrategias de E/A, Bachillerato, España/Portugal.

\section{STRATEGIES TO ANALYZE RHETORICAL DISCOURSE OF ADVERTISING:A MODEL THROUGH ADVERTISEMENTS FROM SPAIN AND PORTUGAL}

\footnotetext{
ABSTRACT: The most important objective of advertising is persuasion and uses all the means available to it and found in rhetoric. In education,

1. Este trabajo se enmarca en el proyecto desarrollado en las estancias de investigación realizadas en 2019 y 2020 en la Universidad de Évora (Portugal), ambas financiadas en convocatoria pública por la Universidad de La Rioja y la Comunidad Autónoma de La Rioja (Resolución 176/2019, de 4 de marzo de 2019 , referencia EICOD19/09; y Resolución 178/2020, de 17 de febrero de 2020, referencia EICOD20/04).
} 
this strategic communication must be properly studied as a complementary model that includes compositional elements and critical reflection. The subject of advertising texts is found in the Baccalaureate curriculum, and for this reason the strategies and modalities used in textbooks are analyzed. There are deficiencies in these textbooks, and for this reason a complete method is offered focused on the development of communication skills (oral and written) and on the interpretation of the elements of advertising persuasion; how complementary applications can be carried out, is exemplified with a cross-cultural comparative analysis of wine advertisements from Spain and Portugal. Therefore, this method of interpretation framed in the educational field develops strategies to comment on the rhetorical advertising discourse in a context in which students must be instructed to interpret the world and create their own opinions.

KEYWORDS: Advertising, rhetorical discourse, teaching/learning strategies, Baccalaureate, Spain/Portugal.

Recibido: 3/11/2020

Aceptado: 28/11/2020

Contacto: Aurora Martínez Ezquerro, Universidad de La Rioja, Facultad de Letras y de la Educación, Edificio Filologías, C/ San José de Calasanz 33, 26004 Logroño (La Rioja). Email: aurora.martinez@unirioja.es

\section{INTRODUCCIÓN}

Los mensajes publicitarios ofrecen una realidad idealizada en la que el hombre progresa porque sus "debilidades" son compensadas mediante la compra de mercancías que le producen deleite y, por tanto, mejora (Eguizábal, 2009). Los anuncios nos hablan más de lo que el consumidor necesita -o sea, desea- que del propio producto porque uno de sus objetivos es crear una conciencia de anhelo constante que muestra solución con la persuasión (Fuentes y Alcaide, 2002) lograda por el uso de los recursos de la retórica publicitaria. Mediante esta comunicación estratégica, el anuncio alcanza sus objetivos y lo hace, según se ha indicado, a partir del uso de las técnicas que la retórica clásica (Quintiliano, 1970) en su orientación pragmática (rethorica utens) empleaba para elaborar sus discursos disuasorios (Spang, 1997 y 2005). La actualidad que revisten los procedimientos de esta disciplina ha sido, según se indica, aprovechada por la publicidad, que conforma un eficaz discurso (Fernández, 2006; Quiles Cabrera, 2012 y 2021) que se arraiga en la sociedad, así en palabras de López Eire (1998, pp. 16-17):

Un buen mensaje publicitario logra algo más que la mera promoción del consumo de un producto, consigue integrarse en ese depósito de la conciencia social donde se sedimentan los rastros de la cultura de masas que la publicidad genera y fomenta. Un buen mensaje publicitario influye en la configuración del código de valores 
sociales por el que se rigen las ideologías y las mitologías de nuestro siglo. [...] El discurso retórico y el mensaje publicitario confluyen porque se dirigen y se refieren ambos a la sociedad y porque ambos tienen como finalidad el objetivo pragmático de la persuasión de los oyentes [...] y porque obedecen y son fieles a un contexto social

Los anuncios ofrecen mensajes que venden valores y significados deliberadamente seleccionados ante los que es preciso formar ciudadanos con capacidad crítica (Sánchez García, 2019). El objetivo del presente artículo parte de la necesidad que en el ámbito de la enseñanza en los últimos cursos de Educación Secundaria (Bachillerato) debe ocupar la instrucción para analizar los componentes retórico-pragmáticos y fomentar la capacidad de opinión. Estamos de acuerdo con Ferraz (1996, p. 9), en que "La publicidad es un fenómeno de una complejidad tal, que obliga, a la hora de definirla, a adoptar un enfoque múltiple". Desde esta perspectiva, realizamos un análisis comparado de los procedimientos y estrategias de enseñanza que los manuales aplican para la instrucción del mensaje publicitario y, a la luz de los resultados, ofrecemos un método completo para comentar los anuncios desde una necesaria perspectiva global, esto es, comunicativa, retórico-pragmática y cultural (Campos Fernández-Fígares, 2020). Es más, en este mundo caracterizado por la globalización, hacemos una cala en el análisis intercultural, mediante un estudio comparativo de los anuncios de vino de España y Portugal, países que pertenecen a la Península Ibérica y que ofrecen una continuidad histórica y social.

\section{Discurso publicitario en libros de texto}

Realizamos un análisis comparado de los métodos y estrategias que los manuales de segundo de Bachillerato emplean en el desarrollo del tema del género discursivo publicitario. Con el fin de concretar cuáles son los elementos curriculares de la publicidad en dicho curso en Lengua Castellana y Literatura II, mostramos lo recogido en el Real Decreto 1105/2014, que establece el currículo básico de este nivel educativo:

\section{Bloque 1. Comunicación oral: escuchar y hablar.}

Contenido: Comprensión y producción de textos orales procedentes de los medios de comunicación social: géneros informativos de opinión. La publicidad.

Criterios de evaluación: 3. Extraer información de textos orales periodísticos y publicitarios procedentes de los medios de comunicación social, reconociendo la intención comunicativa, el tema, la estructura del contenido, identificando los rasgos propios del género periodístico, los recursos verbales y no verbales utilizados valorando de forma crítica su forma de contenido.

Estándares de aprendizaje evaluables: 3.1. Interpreta diversos anuncios sonoros y audiovisuales identificando la información y la persuasión, reconociendo los elementos que utiliza el emisor para seducir al receptor, 
valorando críticamente su forma y su contenido y rechazando las ideas discriminatorias.

\section{Bloque 2. Comunicación escrita: leer y escribir.}

Contenido: La comunicación escrita en el ámbito académico, periodístico, profesional y empresarial. Sus elementos.

Criterios de evaluación: 1. Comprender y producir textos expositivos y argumentativos propios del ámbito académico, periodístico, profesional o empresarial, identificando la intención del emisor, resumiendo su contenido, diferenciando la idea principal y explicando el modo de organización.

Estándares de aprendizaje evaluables: 1.1. Comprende el sentido global de textos escritos de carácter expositivo y argumentativo propios del ámbito académico, periodístico, profesional o empresarial, identificando la intención comunicativa del emisor y su idea principal. 1.2. Sintetiza textos de carácter expositivo y argumentativo propios del ámbito académico, periodístico, profesional o empresarial, diferenciando las ideas principales y las secundarias. 1.3. Analiza la estructura de los textos expositivos y argumentativos procedentes del ámbito académico, periodístico, profesional o empresarial, identificando los distintos tipos de conectores y organizadores de la información textual.

En los manuales estudiados (hemos analizado los empleados de forma general en nuestro contexto, esto es, los que corresponden a las editoriales educativas Oxford, SM, Santillana y Teide) el tema se enuncia mediante el epígrafe "Textos de los medios de comunicación" (e incluye los periodísticos), ocupa una media de cinco páginas dedicadas a las siguientes cuestiones teóricas mostradas como apartados de contenido: definición, características generales, soportes publicitarios, estructura, rasgos lingüísticos y rasgos no lingüísticos (en algunos se añade una sección de publicidad digital). Se observa que junto a la teoría se entreveran ejercicios con preguntas dirigidas a un anuncio seleccionado, son cuestiones similares a las siguientes:

- Indica si cumple el anuncio con las características generales de los textos publicitarios.

- Analiza los elementos que componen el anuncio.

- Explica la relación entre la imagen y el texto verbal.

- Relaciona la importancia de los elementos cromáticos con el eslogan.

- Clasifica el anuncio según su emisor y canal.

- Analiza con qué valores se vincula el producto.

- Identifica la estrategia de persuasión empleada.

- Reconoce los rasgos lingüísticos del titular, el cuerpo y el eslogan.

- Explica los rasgos no lingüísticos del texto. 
- Señala qué acción se pretende del receptor. Relaciónala con los elementos lingüísticos.

- Indica a qué público objetivo se dirige el anuncio.

- Analiza los recursos expresivos.

Estas preguntas y otras parecidas apenas exigen capacidad de interpretación o valoración crítica, responden a un método deductivo y las respuestas de los discentes serán similares, esto es, no dejan de ser una mera reelaboración de la teoría. En dos manuales se añade un apartado específico de comentario global de un anuncio publicitario denominado "Claves para el comentario de un anuncio publicitario", ofrece cuestiones más generales y responde -se han organizado las preguntas- a lo siguiente:

TEMA: eslogan, elementos de la imagen (verbales y no verbales, y su predominio, valores de los elementos simbólicos y connotativos), intención comunicativa, público potencial, tema central y relación con el contexto social y cultural.

ESTRUCTURA: partes que conforman el texto, distribución de los elementos y relaciones (equilibrio, contraste, integración...), imagen y plano, valores connotativos, coherencia y cohesión.

ANÁLISIS TEXTUAL: modalidad textual predominante, léxico, personas gramaticales y tiempos verbales, elementos lingüísticos que aportan cohesión, sintaxis empleada, valores de los recursos no verbales, comentario concreto (se consigue la finalidad deseada, se reproducen tópicos, etc.).

VALORACIÓN CRÍTICA: claridad y eficacia para lograr el propósito, fuerza de la persuasión.

Estas actividades de comentario se emplean habitualmente en la enseñanza, si bien como punto de partida y en función del objetivo y del grupo concreto pueden resultar útiles, pero son insuficientes de forma general para el curso propuesto porque la exigencia académica del nivel curricular debe desarrollar estrategias que supongan una progresión respecto a los saberes y habilidades adquiridos en etapas anteriores. No se aprecia en estos métodos la aplicación del enfoque comunicativo centrado en el uso funcional de la lengua en sus modalidades oral y escrita. Recuérdese que la asignatura se centra en el aprendizaje de las destrezas discursivas (Martínez Ezquerro, 2020) del ámbito, entre otros, de los medios de comunicación, cuyo dominio requiere el uso de procedimientos y el anclaje de conocimientos del funcionamiento del lenguaje en todas sus dimensiones, tanto relativas a los elementos formales como a las normas sociolingüísticas de los intercambios. El currículum mencionado prescribe que esta materia tiene como objetivo crear ciudadanos conscientes e interesados en el desarrollo y la mejora de su competencia comunicativa, personas capaces de interactuar satisfactoriamente en todos los ámbitos que forman y van a formar parte de su vida, pero comprobamos que el trabajo ejercitado no desarrolla convenientemente estas competencias (Martos y Campos Fernández-Fígares, 2012). Para fomentar estas capacidades es necesaria la reflexión sobre los mecanismos empleados en la 
persuasión publicitaria, así como la interpretación y valoración del mundo con el fin de formar opiniones propias.

\section{Método de comentario del discurso retórico publicitario}

Las estrategias de análisis para comentar textos publicitarios deben desarrollar las habilidades comunicativas orales y escritas, y fomentar el juicio crítico para exponer las opiniones propias. Es preciso aplicar un método de análisis del discurso retórico publicitario con enfoque globalizador. Los estudios que ofrecen las estrategias didácticas de comentario no son abundantes para el nivel estudiado (Carbonero Cano, 1992; Gutiérrez Ordóñez, 1997; Arconada Melero, 2006, entre otros); hallamos, en cambio, trabajos centrados en el proceso de la creación publicitaria, que desarroIlan las técnicas que le proporciona la retórica para conseguir la deseada persuasión (Bassat, 2001 y 2006; Figueroa, 1990; Harrison, 1979; García Uceda, 2001 Majocchi y Attanasio, 1980; Obradors Barba, 2007; Moliné, 1988 y 2000; Ortega Martínez, 2004; etc.).

El modelo que proponemos comienza con el análisis conjunto y oral de ejemplos concretos, parte del valor de la inferencia o deducción cooperativa puesto que a medida que se comentan anuncios se muestran cuestiones referidas a los elementos teóricos que estructuran el modelo, esto es, se aplica la inventio o lluvia de ideas. La clave metodológica se centra en la realización inicial de actividades desarrolladas en un espacio de reflexión compartida en el que el profesor guía el discurso mediante preguntas o sugerencias, los alumnos responden, debaten y consensúan. Esta primera fase se va reforzando con la mencionada acción cooperativa (Martínez Ezquerro, 2016b) que el docente va estructurando a la luz de aspectos más precisos del contenido (que se ha ido avanzando en las primeras sesiones y revisando posteriormente). El trabajo final lo constituye un comentario escrito, y su organización se puede apoyar en la guía facilitada pero partiendo de la comprensión fundamental del texto porque es preciso conjugar el análisis con otros conocimientos personales para ofrecer un juicio razonado del mensaje publicitario. Este método permite no solo desarrollar las correspondientes habilidades comunicativas orales y escritas, sino fomentar la capacidad crítica, la negociación de significados, el respeto al compañero, en suma, competencias que ponen de relieve necesarias actitudes en el aula (López Valero y Martínez Ezquerro, 2012).

Mostramos una completa guía pautada que sirve, según se ha indicado, como ayuda para organizar el comentario retórico del discurso publicitario (Pérez Tornero, 1982; Rey, 1992; Sánchez Guzmán, 1993; Ferraz, 1996; Sánchez Corral, 1997; Gurrea, 1999; Romero Gualda, 2005) y recoge los principales elementos que componen un anuncio; la división que ofrece esta taxonomía sirve como apoyo para estructurar sus diferentes elementos. Para su actual elaboración, se han tenido en cuenta las cinco partes empleadas en la elaboración del discurso retórico publicitario, si bien solamente se desarrollan -por evidentes razones- las tres primeras (la práctica oratoria o exposición del trabajo permitiría valorar finalmente la memoria, la actio y la pronuntiatio de un comentario así presentado). Las partes artis son las siguientes: 
1. Inventio: búsqueda de materiales y argumentos propicios para la presentación del producto.

2. Dispositio: ordenación de ideas y argumentos.

3. Elocutio: formulación verbal del discurso, es decir, acomodación de palabras y oraciones a la materia objeto de invención.

4. Memoria: retención en la mente de las ideas, las palabras y su ordenación.

5. Actio y pronuntiatio: regulación de la voz, de los gestos y empleo de una entonación adecuada.

\section{Guía del comentario retórico}

DESCRIPCIÓN GENERAL: producto, marca, anunciante, soporte, tipología y contexto social.

\section{TIPOLOGÍA DE LOS ANUNCIOS}

Según la finalidad:

- Publicidad de venta.

- Publicidad de prestigio.

- Publicidad de concienciación social.

Según la elaboración (predominio):

- Anuncio común de promoción de venta.

- Anuncio elaborado con afán estético.

INVENTIO: búsqueda de materiales y argumentos propicios para la presentación del producto (responde a los elementos que se han valorado inicialmente para diseñar una campaña de publicidad).

1.1. ELEMENTOS INICIALES para la búsqueda de materiales y argumentos:

- TEMA seleccionado: consiste en la idea estratégica que se transmite.

Procedimientos para construir el mensaje diferenciador:

- Propuesta única de venta (USP=Unique Selling Proposition): se elige un atributo principal del producto y se destaca este valor.

- Idea creada por el producto (Copy strategy): el contenido se elabora a partir del beneficio del producto. Consta de tres elementos: ventaja del producto, razón por la que aporta la ventaja y la prueba de que la ventaja/argumento es cierto.

- Personalidad de la marca (Star estrategy): la personalidad está definida por un físico (propiedades materiales o funciones), un carácter (valores y asociaciones) y un estilo (lenguaje específico utilizado en todos sus mensajes). 
Se puede incrementar con alguna de estas variables:

- Lanzamiento de un nuevo producto.

- Desplazamiento de la competencia.

- Incremento de venta.

- RECEPTORES o DESTINATARIOS: potenciales consumidores. Según el público objetivo:

- Publicidad de masas o publicidad selectiva (mayor poder adquisitivo).

- Publicidad según sexo, edad, profesión o geografía.

- Publicidad de productos comunes o altamente especializados (publicidad pseudotécnica o pseudocientífica).

- MEDIO DE DIFUSIÓN o SOPORTE: debe tener en cuenta el texto, los materiales icónicos y los sonoros. Según el soporte:

- Publicidad impresa.

- Publicidad televisada.

- Publicidad en internet (o digital).

- Publicidad radiofónica.

- TONO:

- Serio, conservador, moderado / desenfadado, joven, dinámico.

- Objetivo, informativo / subjetivo, connotativo.

- FORMATO (García Uceda, 2001) o expresión del concepto creativo:

- Narrativa.

- Escenas de la vida real.

- Presentador o busto parlante.

- Testimonial (se subdivide en experto, famoso, persona corriente o personaje insólito).

- Noticia.

- Presencia del producto.

- Problema-solución.

- Demostración.

- Analogía o comparación.

- Cubo de basura.

- Sátira. 
- Musical.

- Fragmentos de cine.

- Dibujos animados.

- Superespectáculo (la grandiosidad, lo nunca visto).

- ESTILO PUBLICITARIO (García Uceda, 2001):

- Informativo-educativo.

- Emotivo: emoción como identificación.

- Regresivo (momentos del pasado).

- Musical.

- Creador de ansiedad visual.

- Humorístico.

- Fantasía.

- Miedo-temor-escándalo.

- Suspense diferido.

- Serie.

- Referencias racionales.

- Erotismo.

\subsection{CRITERIOS DE CALIDAD:}

- Aptum o decorum: tiene en cuenta la adecuación del material descubierto al tema y a los receptores. Se basa en las siguientes relaciones:

- Asunto-público.

- Situación-asunto.

- Credibilidad de la causa.

Es preciso comprobar en qué medida se responde al objetivo y al público objetivo. Este proceso permite distinguir por qué es buena o mala la campaña o qué falla. Para ello es preciso considerar lo siguiente:

- Examinar la coherencia entre la estrategia del mensaje (concepto que se quiere comunicar sobre el producto), la estrategia creativa (idea a través de la que se comunica el concepto al público) y la estrategia de medios (realización o materialización del mensaje en el medio elegido para difundirlo).

- Valorar el grado de adecuación con el público objetivo, sus características, hábitos, estilo de vida, motivaciones, limitaciones y proyecciones. 
1.3. CLINCHER, ACCROCHE o GANCHO: captación inmediata de la atención del espectador. Valoraciones:

- Posibles combinaciones de los códigos icónico y acústico, verbal o extraverbal.

- Función de la captatio benevolentiae.

- Posibilidades del clincher:

- Aspectos insólitos, alienación.

- Producto con defectos.

- Técnica del enigma.

- Argumento de sensibilidad.

- Prestigio del producto.

- Personaje famoso.

- Objetos animados.

1.4. FINALIDAD del anuncio:

- Docere (informar y enseñar): propiedades del producto, aspectos destacables y utilidad del artículo.

- Delectare (entretener y deleitar): aspectos con finalidad de entretenimiento.

- Movere o flectere (apasionar y entusiasmar): lema supremo de toda publicidad.

\subsection{ARGUMENTOS (TOPOI o LOCI) propicios:}

La publicidad participa, según el modelo antiguo, de los géneros demostrativo y deliberativo. En el primero se busca el elogio y la censura de la misma manera que hoy se busca la alabanza de un producto determinado. El deliberativo valora lo bueno y lo perjudicial. Por lo tanto, hay que buscar argumentos plausibles válidos en múltiples ocasiones por ser posibles, es decir, por estar en nuestra mano el poder llevarlos a cabo. Argumentos que ponen de relieve diferentes aspectos:

- Lo excepcional, lo singular, lo único / lo común, lo general, lo universalmente aceptado.

- Lo original, lo personal.

- Lo moderno, lo novedoso, el futuro / lo antiguo, lo clásico, lo tradicional.

- Lo tecnológico, lo artificial / lo natural, lo puro, lo auténtico, lo artesanal.

- La distinción, el refinamiento, el lujo, lo relacionado con grupos sociales prestigiosos / la aceptación masiva.

- La madurez, la seriedad, la experiencia, la seguridad / la juventud, la vitalidad, el dinamismo, la aventura. 
- Lo propio, lo nacional / lo extranjero.

- El placer, las sensaciones agradables, la comodidad.

- El prestigio social, el éxito, el poder.

- La libertad.

- El sexo, el erotismo, la sensualidad.

- Lo ecológico, lo sano, lo light.

- Lo económico.

\subsection{ESLOGAN:}

\section{- Identificación y producto.}

- Objetivo: justificación de sus aspectos generales y de su atracción (poder persuasivo) y fácil memorización (poder evocador).

\section{- Funciones:}

a) Valor con el que se asocia el producto (emoción, instinto - virilidad, sensualidad, inmortalidad, hedonismo...-, creencia, etc.).

b) Procesos de asociación eslogan-mensaje publicitario: semejanza, contraste, contigüidad.

- Categorías: descripción, incitación, prevención contra sustitutos.

- Características: comprensión, brevedad, concisión y atracción.

- Tipos de argumentación: racional y emotiva.

- Lenguaje (se desarrolla en la fase de la elocutio):

a) Planos de la lengua: gráfico, fónico, morfosintáctico y semántico.

b) Recursos retóricos.

\section{DISPOSITIO: ordenación de ideas y argumentos.}

No se refiere solo a los aspectos verbales, sino también a los elementos extralingüísticos de composición como la tipografía, las imágenes y la distribución de los espacios en general.

\subsection{ORDENACIÓN:}

- Ordo naturalis: ordenación que sigue un orden lógico y cronológico natural.

- Ordo artificialis: orden irregular (valoración de saltos en el tiempo).

\subsection{ESTRUCTURA:}

\subsubsection{Subdivisiones:}

1. Anuncio bipartito: puede responder a problema-solución, causaconsecuencia; cambios de espacio, de acción, etc. 
2. Anuncio tripartito: es el más frecuente. Puede dividirse en:

- clincher, cuerpo y eslogan.

- titular o eslogan, cuerpo del texto y pie o cierre del texto.

- apertura (primeros segundos), desarrollo (mayor tiempo) y cierre.

3. Anuncio cuatripartito: es el esquema convencional de los discursos forenses:

- exordium: se puede identificar con el clincher.

- narratio: equivalente a la presentación del producto, que se realiza icónicamente o en combinación con un texto, mayoritariamente en forma de una argumentatio, que corresponde a la descripción de las propiedades y de los valores de uso del producto.

- peroratio: esta función está cubierta por el eslogan cuya función es resumir el anuncio y recordar la marca.

2.2.2. Tipología según la acción y el punto de vista (publicidad audiovisual):

1. Anuncios con una acción y un punto de vista.

2. Anuncios con varias acciones y varios puntos de vista:

- Anuncio maniqueo.

- Anuncio en positivo: el juego del laberinto.

3. Anuncios con idea sonora:

- Idea musical.

- Efecto sonoro.

- Tono de voz.

- Ausencia de sonido.

2.2.3. Componentes gráficos del anuncio (estructura detallada):

1. Imagen.

2. Titulares.

3. Subtitulares.

4. Texto.

5. Epígrafe.

6. Explota.

7. Eslogan.

8. Logotipo. 
2.3. COMBINACIONES IMAGEN Y TEXTO (publicidad gráfica):

1. Solo texto.

2. Solo imagen.

3. Imagen como texto.

4. Texto como imagen.

5. Imagen ilustra el texto.

6. Complementariedad de significado entre imagen y texto.

7. Oposición de sentido entre imagen y texto.

\subsection{SEMIÓTICA DE LA IMAGEN:}

\subsubsection{Plano:}

Encuadre (panorámica, desplazamiento prolongado, movimientos aparentes...), angulación (normal, picado, contrapicado, inclinado...), iluminación (tipología...), composición (foco o mancha, líneas, puntos fuertes, proporciones, colocaciones...), efectos especiales...

\subsubsection{Color:}

Frío o cálido, pálido o dominante, etc., para impactar y para que un objeto destaque del conjunto, para provocar sensaciones o para caracterizar un producto. Uso del blanco y negro (vanguardismo, evocación del cine...).

\subsubsection{Cinésica:}

Capacidad expresiva del rostro (felicidad, alegría, sorpresa, miedo, tristeza...), la mirada (directa o no al receptor) y los gestos y movimientos corporales (expresiones de relajación, placer, satisfacción...).

\subsubsection{Proxémica:}

Relaciones de los personajes entre sí, con el espacio y con el producto.

\subsection{CRITERIOS DE CALIDAD: aptum o decorum.}

- Valorar el grado de adecuación de la ordenación, estructura, componentes, combinaciones, tipología y semiótica del anuncio en relación con la idea que se desea transmitir en el mensaje publicitario.

ELOCUTIO: formulación verbal del discurso.

\subsection{LA LENGUA DE LA PUBLICIDAD (Ferraz, 1996):}

\subsubsection{Características generales y funciones del lenguaje.}

3.1.2. Nivel gráfico (tipos de letra, color, signos extranjerizantes, organización icónica...) y nivel fónico (figuras retóricas y recursos métricos). 


\subsubsection{Nivel morfosintáctico:}

- Economía publicitaria: recursos de condensación, grados de desarrollo del texto y preferencias oracionales.

- Implicación de los receptores: recursos de la función apelativa.

- Ponderación de los productos: recursos.

\subsubsection{Nivel léxico-semántico:}

- Connotación publicitaria: marca publicitaria y asociaciones, vocabulario y estereotipos.

- Creaciones fraseológicas y léxicas: neologismos y juegos con frases hechas.

- Información y redundancia.

3.2. ORNATUS: RECURSOS RETÓRICOS (Spang, 1997 y 2005; García Barrientos, 2000):

\subsubsection{Introducción.}

\subsubsection{Recursos retóricos y función.}

\section{Un modelo a través de anuncios de España y Portugal}

Las posibilidades que ofrece el método aplicado son variadas. Así la propuesta que abordamos toma como base la investigación textual comparada en retórica publicitaria con enfoque intercutural; se muestran, de esta forma, las diversas aplicaciones del análisis, en este caso, de anuncios de vino recogidos en formato impreso en España y Portugal, estudio que pone de relieve, asimismo, la importancia que ofrece fomentar la crítica contrastada de dos culturas en el ámbito de la enseñanza. Reiteramos la importancia de que los estudiantes sean formados para desarrollar la capacidad de interpretar el mundo y de crear sus propias opiniones ante los medios de comunicación.

Las concomitancias que brinda la continuidad histórica y geográfica existente entre España y Portugal, esto es, la Península Ibérica, permiten abordar dos culturas fronterizas. Para realizar el estudio en perspectiva comparada se han analizado textos de publicidad comercial en soporte impreso de ambos países; concretamente, se ha recogido un corpus de anuncios procedentes de periódicos y sus suplementos dominicales, así como de revistas de dichas geografías. Se han consultado los números publicados entre julio y octubre de 2019 y 2020, respectivamente, de los periódicos españoles y sus suplementos dominicales de El Mundo y El País, y de Portugal los que corresponden a Expresso y Público; en cuanto a las revistas españolas, se han seleccionado por su temática, consolidación y número de lectores Muy Interesante y Saber vivir, y las revistas lusas -siguiendo los mismos criterios- han sido las conocidas Visâo y Sábado.

Los números consultados no presentan muchos anuncios; de forma general, se recogen unos cinco en cada número (ocupan una página), y entre estos destacan 
los que publicitan automóviles, perfumes, relojes o joyas, marcas de prestigio del mercado globalizado (Audi, Dior, Rolex, Pandora, etc.) que, por tanto, no individualizan. Los anuncios de alimentación, en cambio, muestran un estilo más autóctono o nacional, razón por la que hemos seleccionado, dentro de este sector, los que corresponden al vino, alimento propio de dos países caracterizados por la amplia producción de caldos de calidad (Miralles, Moretto, y Gomes, 2008). Por tanto, el corpus de la publicidad del vino corresponde a las diversas denominaciones de origen de ambos países y de sus marcas. Mediante el estudio de estos discursos retóricos y, por tanto, pragmáticos se analizan los valores transmitidos en este tipo de bebidas. Los registrados con más frecuencia emplean principalmente los argumentos de armonía, sociabilidad, liderazgo, alegría, placer, diversión, éxito y estilo. Son valores positivos que no transmiten el riesgo que supone consumir bebidas alcohólicas. Recuérdese que debido a la influencia de los anuncios de estos productos (Romero Menon, 2010) fue necesario controlar o limitar la publicidad, especialmente de algunos sectores y, por supuesto, el de las bebidas alcohólicas, que se halla regulado por las leyes de publicidad, como se comprueba en los anuncios seleccionados (incluyen la frase o el sintagma alusivo a la recomendada moderación en la bebida).

En el corpus seleccionado, 30 anuncios de vino (las campañas suelen reiterarse en temporadas concretas), se ha comprobado que en ambos países el tratamiento es similar en cuanto a las técnicas creativas, los elementos retóricos y los mensajes que transmiten. Los anuncios se han ordenado a partir de las siguientes variables coincidentes en ambas geografías: vinos asociados a la celebración y diversión (el caso que vamos a analizar: Vinho Verde y Viña Esmeralda), vinos con tratamiento esquemático de motivos gráficos (vinos especiales o de autor, como EA, Cartuxa y Altos de Tamarón, Ribera del Duero); vinos con imagen central de copa (Alvarinho y Rueda Verdejo); bodegas que muestran sus variedades como un catálogo visual (Casa Ermelinda y Marqués de Riscal, Rioja), etc.

Mostramos el análisis de dos anuncios de vino blanco con características distintivas que, sin embargo, ofrecen puntos en común. El anuncio del vino portugués publicita una denominación de origen (Vinho Verde) y el del vino español una marca concreta de vino blanco catalán. El primero muestra una información amplia y el segundo restringida; enfoques que no impiden que, desde el punto de vista retórico publicitario, se constaten concomitancias, que procedemos a explicar. Destacamos, de nuevo, la libertad que ofrece el método propuesto porque permite desarrollar un discurso continuo que incide en la capacidad de valoración, según se ha indicado. 


\section{Anuncio 1}
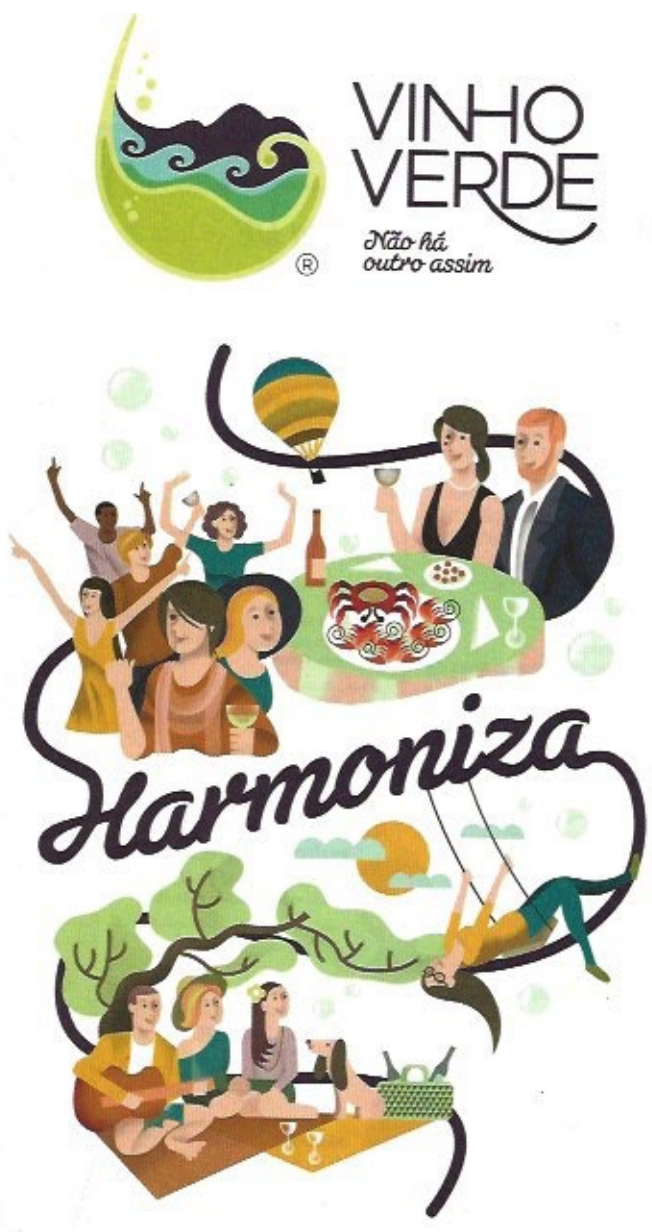

\section{Porque é tempo de se divertir, celebre com Vinho Verde.}

$$
\text { VINHO }
$$

Figura 1. Vinho Verde. Fuente: revista Sábado, n. ${ }^{\circ}$ 796, agosto de 2019

Texto

() Vinho Verde. Nâo há outro assim.

Harmoniza. 
Porque é tempo de se divertir, celebre com Vinho Verde.

Vinho Verde. Comissâo de Viticultura da Regiâo dos Vinhos Verdes. Vinhos de Portugal.

Seja responsável. Beba com moderaçâo. www.vinhoverde.pt

\section{Comentario}

Publicita el texto una denominación de origen propia de Portugal (la DOC Vinho Verde, que independientemente del tipo de vinificación, incluye blancos, rosados, tintos, espumosos, y ahora destilados) y, por tanto, el anuncio es más amplio en su intención puesto que no vende una imagen de marca sino un tipo de vino (que se concretaría en las diversas marcas), esto es, destaca su valor como producto genérico y propio de la tierra lusa. Es una publicidad veladamente informativa que desea seguir captando consumidores y que destaca los productos autóctonos de manera sencilla y natural. Recuérdese que la DOC del Vinho Verde se estableció en 1984 y ocupa la mayor región plantada de viñedos en el país (es el noveno productor de vino en el mundo).

En cuanto al tema, ofrece una idea creada por la propia denominación, esto es, un tipo de vino caracterizado por ser suave, joven y fresco, ideal para aperitivos o comidas ligeras. Es un caldo versátil y así lo muestran los potenciales consumidores de los dibujos (jóvenes y no tan jóvenes) en simultáneos momentos (en espacios naturales y artificiales, lugares que conforman una elipsis) pero siempre asociados a la compañía y a la alegría de una celebración (que bien podría ser cualquier ocasión agradable). De hecho, el verbo "Harmoniza" (función apelativa) responde a una personificación -figura común en la retórica publicitaria- en la que el sujeto presenta duplicidad porque la acción la puede realizar el vino (se entiende, conjugado en presente) o la persona que lo consume (aquí, un imperativo). El mensaje no desea destacar una novedad, sino recordar que es una denominación adecuada para momentos festivos y divertidos, tal y como muestra el diseño desenfadado, casi infantil de los dibujos como extraídos de una viñeta (sin detallar la imagen pero aproximándose al mencionado ambiente lúdico) con colores que también "harmonizan" con la gama cromática del vino que destaca, asimismo, por su versatilidad de momentos y consumidores.

El producto como objeto físico se halla implícito (se adivina la base de la copa de vino en el logo de la denominación "Vinho Verde") en el anuncio porque no interesa precisar las formas, juego que permite, a su vez, dejar a la libre imaginación las múltiples marcas que cada bodega produce. En este ambiente desenfadado hay que respetar la normativa sobre el consumo de bebidas alcohólicas y se recomienda beber con moderación (así reza la frase inserta en la parte superior izquierda en un lateral y escrita en dirección vertical: "Seja responsável. Beba com moderaçâo". A la que se añade la precisa dirección web: www.vinhoverde.pt). Un anuncio que cumple los principios de coherencia y adecuación. 
La ubicación de la palabra "Harmoniza", cuyos extremos abrazan los diversos momentos unidos por el denominador común de la fiesta, actúa como "gancho". Es un anuncio sencillo pero atrayente, y emplea con éxito el simple juego gráfico que enlaza con gracejo imágenes y texto central. La idea de una aparente inocencia o espontaneidad liga con absoluta naturalidad el caldo con el sentido de confraternización y felicidad: la bebida une y harmoniza igual que lo hace la palabra central (y escrita con letra enlazada, grafía caligráfica infantil). El breve eslogan "Nâo há outro assim" (proporciona continuidad a la campaña) habla de la especificidad del producto, de su valor diferenciador frente a otros (recurso muy usado pero no por ello carente del efecto deseado) dentro de la clásica prevención contra sustitutos.

La estructura es tripartita -la más frecuente-. En la parte superior se aprecia la denominación con el eslogan; en el centro -con estructura bimembre- y dominando, se halla el gancho sintetizado en un verbo con dos posibles conjugaciones; y el pie o cierre del texto resume con una explicación que refuerza las imágenes, la necesidad de consumir vino verde para divertirse y celebrarlo. En letras pequeñas figuran dos necesarios logotipos: "Comissâo de Viticultura da Regiâo dos Vinhos Verdes" y "Vinhos de Portugal".

Las características lingüísticas propias de la publicidad se respetan en cuanto a la brevedad y condensación, junto con lo anteriormente señalado. El léxico huye del extranjerismo porque desea reforzar, según se ha indicado, lo autóctono. El campo semántico gira en torno a acciones agradables (divertir), y así el verbo celebrar ha sido elegido por sus connotaciones de festividad y se ha conjugado en imperativo (celebre) -si bien atenuado por el propio contexto- e invita, como el verbo harmonizar, a realizar acciones placenteras asociadas al producto. El argumento cultural del vino relacionado con momentos distendidos forma parte de las costumbres mediterráneas de países como España, que producen y consumen gran cantidad del caldo. Continuidad de hábitos que se aprecia, asimismo, en el anuncio siguiente. 


\section{Anuncio 2}

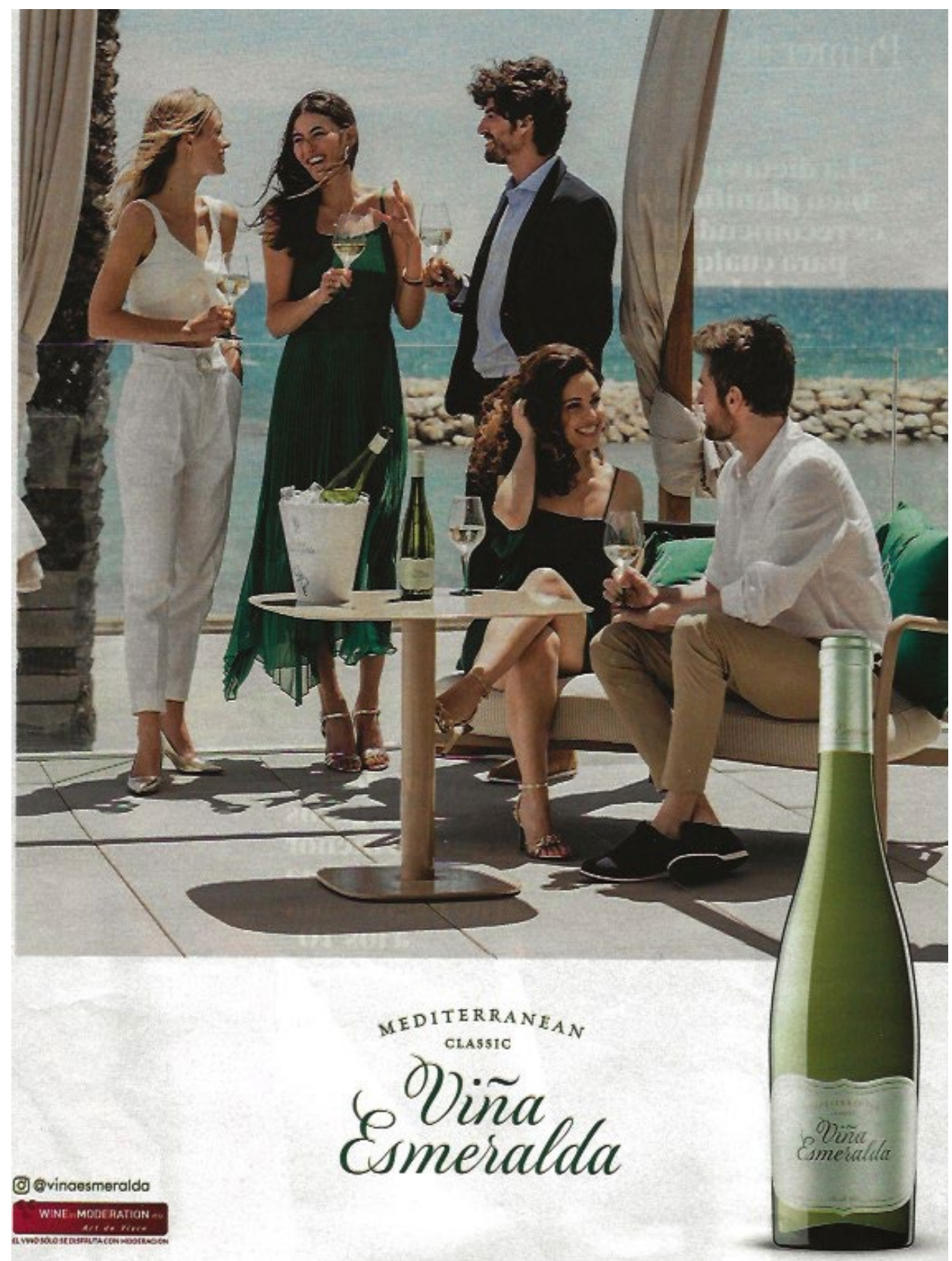

Figura 2. Viña Esmeralda. Fuente: revista Yo dona (El Mundo), n. ${ }^{\circ} 716$, agosto de 2019 
Texto

Mediterranean Classic. Viña Esmeralda.

@ vinaesmeralda. WINE in MODERATION. eu. Art de Vivre. El vino sólo se disfruta con moderación

\section{Comentario}

Corresponde a un anuncio de un producto concreto, un vino del Penedés con DO Catalunya, de unas conocidas bodegas. Es una publicidad en la que predomina el prestigio de la marca porque se conoce $y$, por tanto, se sobreentiende la exquisitez del producto (no es preciso añadir más datos, el principio de la información elidida rige este tipo de objeto comercial). El caldo, al igual que en el caso anterior, se halla asociado a momentos de encuentro feliz y amistoso, si bien en este caso la fotografía (interesa dejar constancia de un espacio real con posibles momentos de celebración, frente al anterior que buscaba la versatilidad que proporcionaban los dibujos de diversas ocasiones) muestra un grupo de jóvenes vestidos con indumentaria formal, con cierto desenfado y sin perder la elegancia; representan los potenciales consumidores, esto es, personas que celebran -o simplemente se reúnen como amigos- un acontecimiento si bien alejado de un estilo rígido. Los argumentos empleados son placer y amistad junto con el prestigio de lo propio o autóctono, este se muestra no solo con palabras, Mediterranean, sino también con la imagen del entorno marítimo o natural. Y es que el mar impregna todo de la misma forma que el vino envuelve la situación, sin olvidar las notas exóticas que ofrece un caldo distinguido (los protagonistas también son distinguidos, pero sin estridencias). El mensaje es claro: el vino se puede disfrutar en diversos momentos, importa lo que permite conseguir, esto es, alegría (sensación) y amistad (sentimiento). Se ha buscado un equilibrio que viene dado, a su vez, por lo que tienen de simbiótico botella y lugar puesto que ambos hablan de una ocasión bebible (celebrable) y de un lugar adecuado para beber.

El continente del vino, no lo olvidemos, es un personaje más que, como tal, se halla en un primer plano a la derecha (donde comienza a fijarse la mirada) y se superpone a la escena central porque demanda su protagonismo. Es un anuncio gráficamente bipartito compuesto por un gran plano de fondo (la escena distendida del grupo de jóvenes que disfrutan bebiendo en un entorno ideal y acorde a las características del caldo) y un pie de imagen con los elementos propios de este tipo de textos publicitarios: el producto/botella/imagen y la marca en el centro. La botella apunta la forma de una gota (el simbolismo es claro), el envase es de un verde delicado que se aproxima al color esmeralda del Mediterráneo y que, con hábil dilogía, evoca el espacio que rodea al grupo de amigos y el predominante tono procedente del mar. Si bien es un diseño de botella de inspiración clásica (como sus consumidores) ofrece un envase actual y glamuroso (véase la forma del escudo y los armónicos colores). El claro guiño a la sofisticación se apoya, asimismo, en el lema, "Mediterranean Classic", elaborado sintagma en inglés que lo convierte en más sofisticado y realza el valor de lo clásico actualizado. 
El propio nombre del vino, Viña Esmeralda, responde a una personificación plena de atributos de sensualidad y belleza (igual que los jóvenes de la feliz escena), es un vino con nombre y apellido, un vino concreto, un vino único, una imagen de marca. El gancho se centra en el prestigio del producto reforzado con las imágenes y la simbología del agua (Martínez Ezquerro, 2016a y 2019). Nos hallamos ante un anuncio adecuado y coherente, basado en el principio de la economía publicitaria propia de anuncios de prestigio. La imagen y la marca son concluyentes: un estilo de vino diferente, adaptado a las modas de sus consumidores, y con un irrebatible mensaje de seducción: placer y amistad. Igual que en el anuncio anterior, el vino se asocia a esos momentos felices y forma parte de la cultura mediterránea, similitudes que, entre otras, ya han sido expuestas.

\section{Conclusiones}

La publicidad invade nuestras vidas y nos transmite la idea de que podemos ser más felices satisfaciendo "necesidades", o sea, consumiendo. El inminente poder de la persuasión se afianza en el empleo de estrategias que conforman discursos eficaces mediante la retórica, que como disciplina -teórica y pragmática- ofrece los recursos y técnicas precisos para convencer. Aquí converge con la publicidad, esta necesita sus herramientas para indagar sobre el lenguaje, revestir el discurso de adecuadas cualidades y conseguir una comunicación efectiva mediante el inventario de consejos y recursos que proporciona. El publicista, al igual que el retórico, compone un mensaje adecuado a las circunstancias porque crea un discurso dirigido que incita a cambiar de opinión, a actuar mental o físicamente sin coacción porque la estrategia de la seducción actúa con disimulado encanto.

Estos mensajes publicitarios requieren, por tanto, ser analizados con visión crítica. Constituyen un tema que se estudia en Bachillerato, nivel curricular en el que el alumno debe desarrollar adecuadamente la capacidad reflexiva ante las múltiples informaciones que le brinda la sociedad. Teniendo en cuenta que el método de E/A aplicado en estos cursos en relación con el comentario de textos publicitarios resulta incompleto, se ha propuesto un flexible método global y gradual que parte de la comprensión fundamental del discurso, desarrolla las competencias comunicativas orales y escritas en el marco del enfoque comunicativo, integra conocimientos personales y fomenta el juicio razonado del texto. La flexibilidad que ofrece permite, asimismo, construir un discurso argumentado con cierta libertad (la guía proporcionada huye de la rigidez en su aplicación) que muestra la madurez en la adquisición de competencias del estudiante.

Esta útil herramienta metodológica de análisis de retórica publicitaria ofrece posibilidades de estudio comparado desde diversas perspectivas, como la social (roles de género), la cultural (costumbres), la internacional (mercado globalizado), etc. A modo de ejemplo, se ha realizado desde este enfoque el comentario de anuncios de vino de España y Portugal; constituyen estos países un caso de continuidad histórica y, por ende, social y cultural, que puede ser extrapolado al análisis de discursos de otras geografías. El estudiante en formación aprende a interpretar 
paulatinamente el mensaje con el fin de conocer sus claves sociales, culturales, pragmáticas, compositivas, etc.

Este método global permite, asimismo, que el alumno domine estrategias que fomentan las habilidades del nivel curricular correspondiente y fomenta la necesaria capacidad crítica ante los mensajes persuasivos que esconden, según se ha indicado, un estudiado y eficaz discurso ante el que hay que estar prevenido e instruido, instruido y prevenido.

\section{REFERENCIAS BIBLIOGRÁFICAS}

Arconada Melero, M. Á. (2006). Cómo trabajar con la publicidad en el aula. Barcelona: Graó.

Barthes, R. (1990). El mensaje publicitario, en La aventura semiológica. Barcelona: Paidós, 239-243.

Bassat, L. (2001). El libro rojo de la publicidad (Ideas que mueven montañas). Barcelona: Debolsillo.

Bassat, L. (2006). El libro rojo de las marcas (Cómo construir marcas de éxito). Barcelona: Debolsillo.

Campos Fernández-Fígares, M. (2020). Enfoque intercultural para la creación de un corpus literario en el aula de ELE. Portalinguarum, 34, 39-53.

Carbonero Cano, P. (1992). Modalidades enunciativas en los textos publicitarios. En Ariza, Manuel (ed.), Problemas y métodos en el análisis de textos. In memoriam Antonio Aranda (pp. 109-122). Sevilla: Secretariado de Publicaciones de la Universidad.

Eguizábal, R. (2009). Industrias de la conciencia. Una historia social de la publicidad en España. Barcelona: Península.

Fernández, E. (2006). Retórica clásica y publicidad. Logroño: Instituto de Estudios Riojanos.

Ferraz, A. (1996). El lenguaje de la publicidad. Madrid: Arco/Libros.

Figueroa, R. (1990). Cómo hacer publicidad. Un enfoque teórico-práctico. México: Pearson Educación.

Fuentes, C. y Alcaide, E. R. (2002). Mecanismos lingüísticos de la persuasión. Madrid: Arco/Libros.

Gaillot, M. (1995). Essai sur la langue de la réclame contemporaine. Toulouse: Privat.

García Barrientos, J. L. (2000). Las figuras retóricas. El lenguaje literario 2. Madrid: Arco/Libros.

García Uceda, M. (2001). Las claves de la publicidad. Madrid: ESIC.

Gurrea, Á. (1999). Los anuncios por dentro. Bilbao: Universidad del País Vasco. 
Gutiérrez Ordóñez, S. (1997). Comentario pragmático de textos publicitarios. Madrid: Arco/Libros.

Harrison, T. (1979). Manual de técnicas de publicidad. Bilbao: Ediciones Deusto.

Lausberg, H. (1975). Manual de retórica literaria. Madrid: Gredos, 3 vols.

Ley General de Publicidad. Ley 34/1988, de 11 de noviembre, Ley General de Publicidad. BOE» núm. 274, de 15/11/1988. Obtenido el 22 de octubre de 2020 desde https://www.boe.es/buscar/act.php?id=BOE-A-1988-26156.

López Eire, A. (1997). Retórica clásica y teoría literaria moderna. Madrid: Arco/Libros.

López Eire, A. (1988). La retórica en la publicidad. Madrid: Arco/Libros.

López Valero, A. y Martínez Ezquerro, A. (2012). Aprendizaje y enseñanza de la Lengua Castellana y Literatura: currículo de ESO. Contextos Educativos, 15, 27-40.

Majocchi, R. y Attanasio, F. (1980). Cómo hacer publicidad. Bilbao: Ediciones Deusto.

Martínez Ezquerro, A. (2016a). Voces, lecturas y símbolos del agua en los anuncios publicitarios. En I. Morales, S. Robles, S. y M. da N. Pires (eds.), Lecturas del agua: un acercamiento interdisciplinar desde la cultura y el turismo (pp. 299-312). Madrid: Catarata.

Martínez Ezquerro, A. (2016b). El método de cooperación interpretativa como estrategia lectora, Álabe, 14. http://doi.org/10.15645/Alabe2016.14.1

Martínez Ezquerro, A. (2019). De los tópicos ambientales a la retórica publicitaria: semántica de la naturaleza. En M. Campos Fernández-Fígares (coord.), Imaginarios de la naturaleza y de la cultura del agua (pp. 127-144). Madrid: Marcial Pons.

Martínez Ezquerro, A. (2020). Habilidades lingüísticas en prácticas lectoras interculturales. Porta Linguarum. Revista Internacional de Didáctica de las Lenguas Extranjeras, 34-junio, 107-123.

Martos Nuñez, E. y Campos Fernández-Fígares, M. (2012). La lectura y la escritura en el siglo XXI: Cultura letrada y modernidad. Álabe, 5. http://doi.org/10.15645/ Alabe.2012.5.13

Miralles, C.; Moretto, L. y Gomes, V. (2008). Gestâo de marcas e arranjos produtivos: A marca "Vinho do Porto". Comportamento Organizacional e Gestaçâo, 14 (1), 85-95.

Moliné, M. (1988). La comunicación activa. Publicidad sólida. Bilbao: Ediciones Deusto.

Moliné, M. (2000). La fuerza de la publicidad. Madrid: Mc Graw Hill-Universidad Antonio de Nebrija.

Moliner, M. (2007). Diccionario de uso del español. Madrid: Gredos, 3. ${ }^{\mathrm{a}}$ ed.

Muñoz Espinalt, C. (1963). Psicología de la publicidad. Barcelona: Toray. 
Obradors Barba, M. (2007). Creatividad y generación de ideas. Estudio de la práctica creativa en cine y publicidad. Barcelona: Universidad de Valencia-UAB.

Ortega Martínez, E. (2004). La comunicación publicitaria. Madrid: Pirámide.

Palmer, Í. y Campos Fernández-Fígares, M. (2019). Adivinanzas en el aula de ELE: literatura oral, patrimonio e innovación educativa. Tejuelo, 30, 289-316.

Pérez Tornero, J. M. (1982). La semiótica en la publicidad. Barcelona: Mitre.

Pujante, D. (1999). El hijo de la persuasión. Quintiliano y el estatuto retórico. Logroño: Instituto de Estudios Riojanos, 2. ${ }^{\mathrm{a}}$ ed.

Quiles Cabrera, M. C. (2011). La competencia comunicativa en la Educación Superior: en torno a los indicadores para su seguimiento y evaluación. ED.UCO. Revista de investigación educativa, 5, 59-74.

Quiles Cabrera, M. C. (2012). El rescate de la palabra: discurso, oralidad y educación lingüística en la escuela. En R. Sánchez García y A. Ramos (coords.), Compromiso docente y realidad educativa: retos para el maestro del siglo XXI (pp. 219-232). Madrid: Síntesis.

Quiles Cabrera, M. C. (2016). Una red de lecturas: interdisciplinariedad, innovación docente y educación superior. En T. Rösing, T. y M: Rettenmaier (coords.), Lectura, arte y patrimonio: rediseñando redes (pp. 27-48). Passo Fundo: Universidad de Passo Fundo.

Quiles Cabrera, M. C. (2021). Discurso publicitario e intertextualidad: itinerarios para la formación comunicativa del profesorado. Educação \& Formação. 6-1, jan./abr, $1-26$.

Quintiliano, M. F. (1970). Institutionis oratoriae libri duodecim. Edición de M. Winterbottom. Oxford: Oxford University Press.

Real Academia Española (2014). Diccionario de la Lengua Española. Barcelona: Espasa Libros.

Real Decreto 1105/2014, de 26 de diciembre, por el que se establece el currículo básico de la Educación Secundaria Obligatoria y del Bachillerato (BOE, 3 de enero de 2015).

Rey, J. (1992). La significación publicitaria. Sevilla: Alfar.

Reyzábal, M. V. (2002). Didáctica de los discursos persuasivos. Madrid: La Muralla.

Romero Gualda, M. V. (coord.) (2005). Lenguaje publicitario. La seducción permanente. Barcelona: Ariel.

Romero Menon, W. (2010). O que comunica a publicidade? Elementos hermenéuticos para uma estética da publicidade. Revista do Programa de Pós-graduaçào em Comunicaçâo, 4-2, 1-10.

Sánchez Corral, L. (1997). Semiótica de la publicidad. Narración y discurso. Síntesis: Madrid. 
Sánchez García, R. (coord.) (2018). Nuevas poéticas y redes sociales. Joven poesía española en la era digital. Madrid: Siglo XXI.

Sánchez García, R. (2019). Sobre la cuestión del canon y las lecturas escolares ante los nuevos espacios de lectura. En M. Campos Fernández-Fígares y M. C. Quiles (coords.), Repensando la didáctica de la lengua y la literatura. Paradigmas y líneas emergentes de investigación (pp. 131-144). Madrid: Visor.

Sánchez Guzmán, J. R. (1993). Teoría de la publicidad. Madrid: Tecnos.

Spang, K. (1997). Fundamentos de retórica. Pamplona: Eunsa.

Spang, K. (2005). Persuasión. Fundamentos de retórica. Pamplona: Eunsa. 